\title{
Biatrial vs Bicaval Orthotopic Heart Transplantation: A Systematic Review and Meta-Analysis
}

\author{
Casper F. Zijderhand, BSc, ${ }^{*}$ Kevin M. Veen, BSc, ${ }^{*}$ Kadir Caliskan, MD, PhD, \\ Tamar Schoonen, BSc, M. Mostafa Mokhles, MD, PhD, Jos A. Bekkers, MD, PhD, \\ Olivier C. Manintveld, MD, PhD, Alina A. Constantinescu, MD, PhD, \\ Jasper J. Brugts, MD, PhD, Ad J. J. C. Bogers, MD, PhD, and \\ Johanna J. M. Takkenberg, MD, PhD \\ Department of Cardiothoracic Surgery, Erasmus University Medical Center, Rotterdam, the Netherlands; and Department of \\ Cardiology, Erasmus University Medical Center, Rotterdam, the Netherlands
}

\begin{abstract}
Background. Orthotopic heart transplantation (OHT) is the gold standard treatment in end-stage heart disease. Controversy remains whether bicaval OHT is superior to biatrial OHT in both early and late outcomes. This study aimed to provide an overview of the early and late outcomes in patients who underwent a bicaval or biatrial OHT.

Methods. A systematic literature search was performed for articles published before December 2017. Studies comparing adult patients undergoing biatrial OHT and bicaval OHT were included. Early outcomes were pooled in odds ratios and late outcomes were pooled in rate ratios. Late survival was visualized by a pooled KaplanMeier curve.

Results. A total of 36 publications were included in the meta-analysis, counting 3555 patients undergoing biatrial OHT and 3208 patients undergoing bicaval OHT. Early outcomes in mortality, tricuspid regurgitation, mitral
\end{abstract}

$\mathrm{O}$ rthotopic heart transplantation (OHT) remains the gold standard for patients with end-stage heart failure. ${ }^{1}$ The standard biatrial OHT technique was introduced by Lower and Shumway in $1960^{2}$ and is still widely used because of its relative simplicity. This technique only requires 2 anastomoses to the atria of the recipient. Yacoub and colleagues ${ }^{3}$ introduced the bicaval OHT technique in 1989, and it has gained popularity since. The bicaval technique requires a single left atrial anastomosis and separate caval suture lines. However, controversy regarding the preferred surgical OHT technique remains. There is a broad variety of studies that describe potential differences in outcome between the 2 surgical techniques. The biatrial technique tends to be less technical challenging for cardiac implantation, which results in a

* Mr Zijderhand and Mr Veen contributed equally to this work.

Address correspondence to Mr Zijderhand, Thoraxcenter, Rg-619, Erasmus MC, University Medical Center Rotterdam, Dr Molewaterplein 40, 3015 GD Rotterdam, the Netherlands; email: c.zijderhand@eramusmc.nl. regurgitation, and permanent pacemaker implantation differed significantly in favor of the bicaval OHT patients. Long-term survival was significantly better in patients undergoing bicaval vs biatrial OHT (hazard ratio, $1.32 ; 95 \%$ confidence interval, 1.1-1.6; $P=.008$ ). Also, late tricuspid regurgitation was less frequently seen in the bicaval OHT patients (rate ratio, 2.14; 95\% CI, 1.173.94; $P=$.014).

Conclusions. This systematic review with metaanalysis shows that bicaval OHT results in more favorable early and late outcomes for patients undergoing a bicaval OHT compared with a biatrial OHT. Therefore, bicaval OHT should be considered as preferable technique for OHT.

(Ann Thorac Surg 2020;ா:ロ-匹) (C) 2020 by The Society of Thoracic Surgeons

reduced ischemic time of the allograft. ${ }^{4,5}$ However, the biatrial technique is known for worse hemodynamics because of the redundant atrial tissue and an increased risk of atrial arrhythmias in the postoperative period. The bicaval technique is more complicated and, therefore, might require a longer operation times. However, the bicaval technique leads to improved hemodynamics and a lower incidence of atrial arrhythmias in the postoperative period. ${ }^{6,7}$ Unfortunately, most reported studies are insufficiently powered to detect important differences. Therefore, a systematic review and meta-analysis was conducted to assess the possible advantages in early and late posttransplantation outcomes in patients who underwent biatrial OHT compared with bicaval OHT.

The Supplemental Material can be viewed in the online version of this article [http://doi.org/10.1016/j. athoracsur.2019.12.048] on http://www.annalsthoracic surgery.org. 


\section{Material and Methods}

\section{Search Strategy}

To establish an overview of reported outcome, a systematic literature search, according to the PRISMA (Preferred Reporting Items for Systematic Reviews and Meta-Analysis) guidelines, was conducted (Supplemental Text 1). ${ }^{8}$ Search terms were developed in collaboration with a dedicated librarian in our center. On December 15, 2017, Embase, MEDLINE, Cochrane, Web of Science, and Google Scholar were searched (search terms are provided in Supplemental Text 2). Inclusion and exclusion criteria were defined a priori. Randomized controlled trials and observational studies concerning adult patients undergoing OHT comparing the standard biatrial $\mathrm{OHT}$ and the bicaval OHT were included. Studies with less than 20 patients, poster publications, abstracts, and conference summaries were excluded. Studies with less than 20 patients were excluded because these studies were most likely early experiential series and do not reflect the general population. Posters and abstracts were not included because these formats did not undergo extensive peer reviewing. In the case of overlapping study populations, the study with the most patient-years of follow-up were selected. Exceptions were made for studies that reported on more outcomes of interest. Furthermore, non-English studies were excluded. Two researchers (C.F.Z. and K.M.V.) independently reviewed abstracts and full texts in an unblinded standardized manner. In case of disagreement to include a study, an agreement was negotiated.

\section{Data Extraction}

Study design, year of surgery, and follow-up (patientyears and mean) were documented. If follow-up was not provided, patient-years were calculated by multiplying the number of patients with the mean follow-up (or median if the mean was not provided). The baseline characteristics extracted from the individual studies are displayed in Supplemental Table 1. In addition, the following procedural characteristics were extracted: cardiopulmonary bypass time, aortic cross-clamp time, length of hospital stay, and ischemic time. The following posttransplantation outcomes were extracted and documented as early (in-hospital or $<30$ day[s]) or late (out-ofhospital or $>30$ days): mortality, tricuspid regurgitation, mitral regurgitation, and pacemaker implantation. The length of hospital stay was defined as the day the patient received the OHT till the day the patient was dismissed from the hospital after the transplant. The individual study definitions were used to define the outcomes. Data were independently extracted by 2 authors (C.F.Z. and T.S.). The Newcastle-Ottawa Scale was used to assess the methodological quality of the studies. ${ }^{9}$

\section{Statistical Analyses}

Log-transformed inverse variance-weighted pooled baseline characteristics were calculated. To compare baseline and procedural characteristics, in cases of descriptive data, odds ratios (ORs) were used, and in cases of categorical data, mean differences were used. The ORs and mean differences were calculated with the use of a fixed-effects model, as the goal was to compute comparisons for the identified population, and not to generalize to other populations, and an assessment of baseline characteristics similar in most cases..$^{10} \mathrm{~A} P$ value less than .05 was considered statistically significant and a $95 \%$ confidence interval (CI) was calculated. Continuous data were presented as mean with $95 \% \mathrm{CI}$ and discrete variables were presented as percentage with $95 \%$ CI. Random-effects models using the DerSimonian-Laird method were used to pool outcomes. ${ }^{11}$ ORs were used for dichotomous data for early outcomes, and rate ratios (RRs) were used for dichotomous data for late outcomes. The Cochrane $\mathrm{Q}$ statistic and $\mathrm{I}^{2}$ were used to assess heterogeneity. Egger's test and funnel plots were used to assess the risk of publication bias. ${ }^{12}$ Comprehensive Meta-Analysis v2.2.064 (Biostat, Engelwood, NJ) was used to calculate the pooled outcomes and to generate forest and funnel plots. Patient survival was visualized in a pooled Kaplan-Meier (KM) curve derived from the originally published KM curves using the method described by Guyot and colleagues. ${ }^{13}$ The Engauge Digitizer v10.0 $0^{14}$ was used to create a list of coordinates of the KM curve, and an algorithm written in $\mathrm{R}$ (version 3.3.3; R Foundation for Statistical Computing, Vienna, Austria) was employed to reconstruct the original patient data. Thereafter, GraphPad Prism version 7.00 for Windows (GraphPad Software, San Diego, CA) was used to plot the pooled KM curve. The reconstructed data were used to obtain hazard ratios (HRs) of late mortality in the biatrial and bicaval groups by univariable Cox regression. Thereafter, the HRs were pooled using Comprehensive Meta-Analysis. In order to evaluate whether studies before the year 2000 yielded different conclusions compared with contemporary studies, a subgroup analysis was performed.

\section{Results}

The literature search resulted in 3648 studies, of which 45 articles met the inclusion criteria. Owing to overlapping data, 9 studies had to be excluded, resulting in 36 inclusions for the meta-analysis (Figure 1). References are represented together with the baseline characteristics of all individual studies in Supplemental Table 1 (References S1-S36). The meta-analysis included 6763 patients who had underwent OHT, of whom $3555(52.6 \%)$ received a biatrial OHT and $3208(47.4 \%)$ received a bicaval OHT. The median year of operation in the biatrial group was 1996 (range, 1988-2005) and in the bicaval group was 1998 (range: 1990-2005). Of the 36 studies, 32 were observational studies and 4 studies were randomized (References S1, S4, S14, and S17 in Supplemental Table 1). The biatrial group contained 1911 patients who had reported a mean follow-up time of $6.2 \pm 8.8$ years, encompassing 11,833 patient-years. The bicaval group contained 1935 patients who had reported a mean follow-up time of $6.5 \pm 10.2$ years, encompassing 12,601 patient-years. All studies scored between 5 and 9 points on the Newcastle-Ottawa 


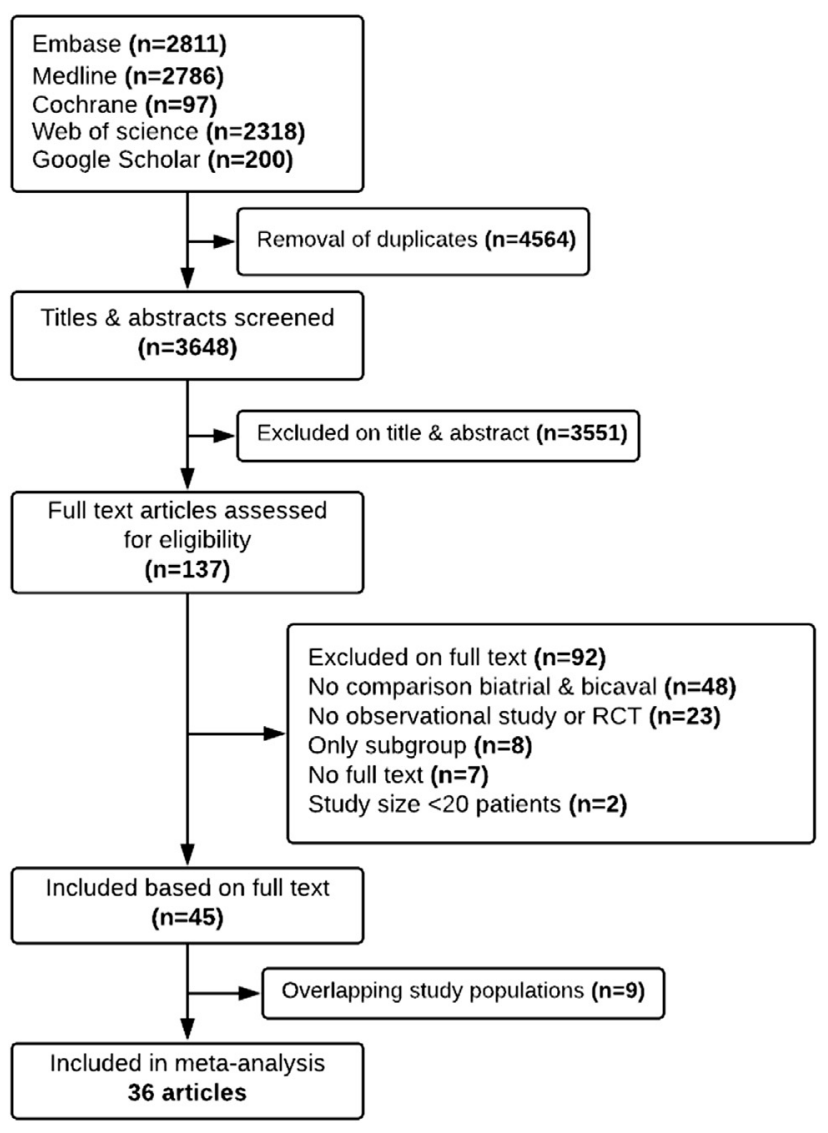

Figure 1. Flowchart of included studies in the meta-analysis.

Scale and most studies lost points on comparability (Supplemental Table 1).

\section{Baseline and Procedural Characteristics}

Pooled baseline and procedural characteristics of the 6763 patients included in the meta-analysis are shown in Table 1.

\section{Early Outcomes}

A forest plot containing the individual and pooled ORs for the early outcomes of mortality, tricuspid regurgitation, mitral regurgitation, and pacemaker implantation is presented in Figures 2A to 2D. The pooled early mortality in the biatrial group was $12.5 \%$ (95\% CI, $8.3 \%$ $18.4 \%$ ) and in the bicaval group was $8.8 \%$ (95\% CI, $4.8 \%$ $15.5 \%)$, with an OR of $1.47(95 \% \mathrm{CI}, 1.0-2.2 ; P=.048)$. Furthermore, early moderate-to-severe tricuspid regurgitation, early moderate-to-severe mitral regurgitation, and need of early pacemaker implantation were observed more frequently in the biatrial OHT group (Table 2).

\section{Late Outcomes}

The meta-analyses contained 10 studies (References S13, S14, S18, S21, S22, S26, S27, S32, S33, and S36 in Supplemental Table 1) that reported KM curves that could be pooled. The KM curves showed differences in late mortality between the biatrial and bicaval groups (Figure 3). The 2-year, 5-year, and 10-year survival rates were $80.0 \%$ $\pm 0.1 \%, 71.0 \% \pm 0.1 \%$, and $60.1 \% \pm 0.2 \%$ in the biatrial group and $84.3 \% \pm 0.01 \%, 76.8 \% \pm 0.1 \%$, and $71.2 \% \pm$ $0.2 \%$ in the bicaval group, respectively. Pooled HR for late mortality showed a significantly higher risk in the biatrial group, with an HR of $1.32(95 \% \mathrm{CI}, 1.1-1.6 ; P=.008)$ and an $\mathrm{I}^{2}$ of $38.0 \%$. The linearized occurrence rates of late outcomes of the individual transplant groups are presented in Table 2. Data on late tricuspid regurgitation were reported in 8 studies and showed a significant difference in favor of the bicaval group, with a linearized occurrence RR of 2.14 (95\% CI, 1.17-3.94; $P=.014$ ) (Supplemental Figure 1A). Late mitral regurgitation was reported in 6 studies, with a linearized occurrence RR of 1.23 (95\% CI, 0.64-2.37; $P=.528$ ) (Supplemental Figure 1B). Late pacemaker implantation was reported in 8 studies and had a linearized occurrence RR of $1.93(95 \%$ CI, 0.92-4.10; $P=.083$ ) (Supplemental Figure 1C).

Table 1. Pooled Baseline and Procedural Characteristics of Included Studies

\begin{tabular}{|c|c|c|c|c|c|c|}
\hline Variable & Biatrial $(\mathrm{n}=3555)$ & Bicaval $(\mathrm{n}=3208)$ & OR/MD $(95 \% \mathrm{CI})$ & $P$ Value & Studies Reported & $\mathrm{I}^{2}(\%)$ \\
\hline Age, $\mathrm{y}^{\mathrm{a}}$ & $50.5(50.0-51.0)$ & $50.3(49.8-50.8)$ & $-0.63(-1.42$ to 0.16$)$ & .118 & 23 & 54.0 \\
\hline Male, $\%^{b}$ & $82.6(81.0-84.2)$ & $77.6(75.6-79.5)$ & 1.31 (1.12 to 1.55$)$ & .002 & 27 & 47.8 \\
\hline Systolic PAP, mm $\mathrm{Hg}^{\mathrm{a}}$ & $40.7(38.8-42.6)$ & $41.7(39.6-43.8)$ & $-1.64(-4.55$ to 1.28$)$ & .272 & 6 & 48.0 \\
\hline $\mathrm{CVP}, \mathrm{mm} \mathrm{Hg}{ }^{\mathrm{a}}$ & $5.37(5.10-5.63)$ & $3.48(3.22-3.75)$ & $1.01(0.62$ to 1.41$)$ & $<.001$ & 9 & 76.6 \\
\hline Ischemic etiology, $\%{ }^{b}$ & $39.5(37.1-41.9)$ & $36.8(34.2-39.5)$ & $1.10(0.94$ to 1.28$)$ & .245 & 19 & 0.0 \\
\hline Diabetes, $\%^{\mathrm{b}}$ & $29.6(25.5-34.1)$ & $26.6(22.2-31.6)$ & $1.10(0.79$ to 1.52$)$ & .573 & 5 & 52.9 \\
\hline $\mathrm{CPB}, \min ^{\mathrm{a}}$ & $116.5(103.3-129.6)$ & $126.8(111.0-142.5)$ & $-9.90(-21.7$ to 1.9$)$ & .099 & 11 & 90.2 \\
\hline Aortic cross-clamp time, $\min ^{a}$ & $64.7(53.3-76.1)$ & $75.0(58.5-91.6)$ & $-10.15(-20.8$ to 0.5$)$ & .062 & 6 & 93.4 \\
\hline Ischemia time, $\min ^{a}$ & $164.7(162.8-166.6)$ & $174.8(165.8-183.9)$ & $-16.7(-27.7$ to -4.3$)$ & .007 & 25 & 93.8 \\
\hline Length of hospital stay, $\mathrm{d}^{\mathrm{a}}$ & $26.2(19.3-33.2)$ & $25.1(17.4-32.9)$ & $1.07(-2.82$ to 4.95$)$ & .590 & 7 & 70.0 \\
\hline
\end{tabular}

\section{${ }^{\mathrm{a}} \mathrm{MD} \quad{ }^{\mathrm{b}} \mathrm{OR}$}

Values are median (interquartile range).

$\mathrm{CI}$, confidence interval; $\mathrm{CPB}$, cardiopulmonary bypass time; $\mathrm{CVP}$, central venous pressure; $\mathrm{MD}$, mean difference; OR, odds ratio; PAP, pulmonary artery pressure. 
A

Early mortality

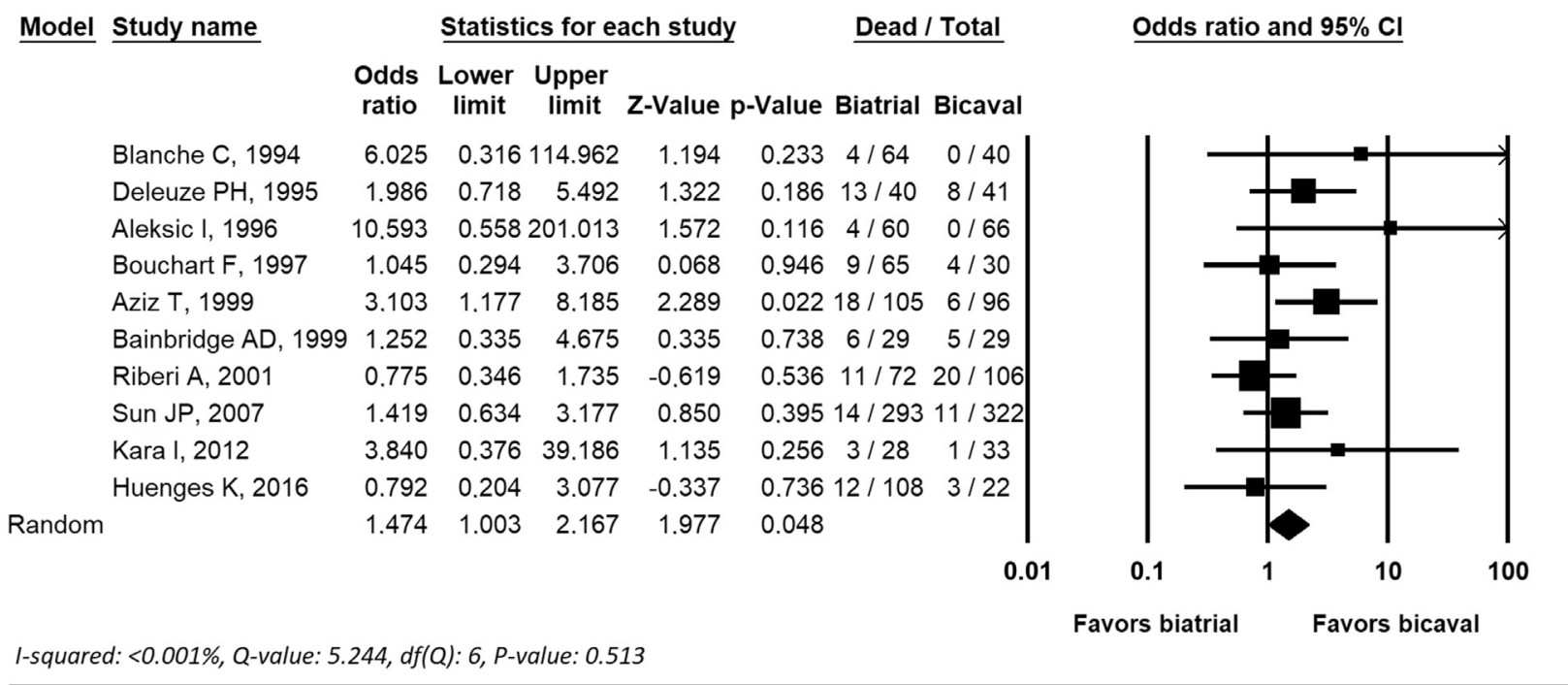

\section{B Early moderate-to-severe tricuspid regurgitation}

\begin{tabular}{|c|c|c|c|c|c|c|c|c|}
\hline \multirow[t]{2}{*}{ Model } & \multirow[t]{2}{*}{ Study name } & \multicolumn{5}{|c|}{ Statistics for each study } & \multicolumn{2}{|c|}{ TR / Total } \\
\hline & & $\begin{array}{l}\text { Odds } \\
\text { ratio }\end{array}$ & $\begin{array}{c}\text { Lower } \\
\text { limit }\end{array}$ & $\begin{array}{c}\text { Upper } \\
\text { limit }\end{array}$ & Z-Value & p-Value & Biatrial & Bicav \\
\hline & Deleuze PH, 1995 & 3.689 & 1.327 & 10.258 & 2.502 & 0.012 & $233 / 40$ & $23 / 41$ \\
\hline & Leyh RG, 1995 & 4.000 & 0.799 & 20.017 & 1.687 & 0.092 & $8 / 12$ & $5 / 15$ \\
\hline & Aziz T, 1999 & 1.698 & 0.883 & 3.266 & 1.586 & 0.113 & $331 / 105$ & $19 / 96$ \\
\hline & Milano CA, 2000 & 2.537 & 1.231 & 5.229 & 2.523 & 0.012 & $229 / 68$ & $17 / 75$ \\
\hline & Wang SS, 2000 & 5.250 & 1.624 & 16.974 & 2.770 & 0.006 & $27 / 39$ & $6 / 20$ \\
\hline & Solomon NA, 2004 & 7.394 & 0.369 & 148.300 & 1.308 & 0.191 & $13 / 38$ & $0 / 37$ \\
\hline & Koch A, 2005 & 1.275 & 0.749 & 2.169 & 0.895 & 0.371 & $137 / 139$ & $35 / 158$ \\
\hline & Sun JP, 2007 & 1.582 & 1.052 & 2.377 & 2.205 & 0.027 & $766 / 293$ & $50 / 322$ \\
\hline & Kalra N, 2010 & 1.557 & 0.250 & 9.689 & 0.474 & 0.635 & $55 / 57$ & $53 / 56$ \\
\hline & Kara I, 2012 & 7.077 & 2.147 & 23.329 & 3.215 & 0.001 & $123 / 28$ & $13 / 33$ \\
\hline & Wartig M, 2014 & 1.973 & 1.252 & 3.109 & 2.928 & 0.003 & $363 / 221$ & $38 / 226$ \\
\hline & Huenges K, 2016 & 1.086 & 0.333 & 3.548 & 0.137 & 0.891 & $121 / 108$ & $4 / 22$ \\
\hline & Rivinius R, 2017 & 0.664 & 0.356 & 1.241 & -1.283 & 0.199 & $924 / 161$ & $24 / 115$ \\
\hline Random & & 1.915 & 1.376 & 2.665 & 3.855 & 0.000 & & \\
\hline
\end{tabular}

I-squared: $65.6 \%$, Q-value: $34.929, d f(Q): 12, P$-value: $<0.001$

\section{Odds ratio and $95 \% \mathrm{Cl}$}

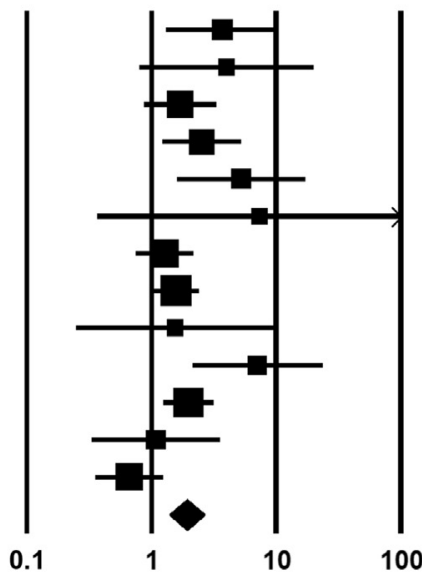

Favors biatrial

Favors bicaval

Figure 2. Forest plots of $(A)$ early mortality, (B) moderate-to-severe tricuspid regurgitation (TR), (C) moderate-to-severe mitral regurgitation $(M R)$, and $(D)$ permanent pacemaker (PM) implantation. CI, confidence interval.

\section{Subgroup Analysis}

Subgroup analysis of the 4 randomized controlled trials was only possible for early permanent pacemaker implantation, as other outcomes were reported in less than 3 individual studies and no pooling attempt was made. Early permanent pacemaker implantation was comparable in these 3 studies. Subgroup analysis of the observational studies did not lead to a change in significance in any of the outcomes.
Subgroup analyses of studies published before and after year 2000 did not lead in changes in significance in any of the outcomes.

\section{Publication Bias and Sensitivity Analysis}

Early and late outcomes did not show publication bias according to Egger's test. Funnel plots are presented in Supplemental Figures 2A to 2D for early outcomes and Supplemental Figures 3A to 3C for late outcomes. 


\section{Early moderate-to-severe mitral regurgitation}

\begin{tabular}{|c|c|c|c|c|c|c|c|c|}
\hline \multirow[t]{2}{*}{ Model } & \multirow[t]{2}{*}{ Study name } & \multicolumn{5}{|c|}{ Statistics for each study } & \multicolumn{2}{|c|}{ MR / Total } \\
\hline & & $\begin{array}{l}\text { Odds } \\
\text { ratio }\end{array}$ & $\begin{array}{l}\text { Lower } \\
\text { limit }\end{array}$ & $\begin{array}{c}\text { Upper } \\
\text { limit }\end{array}$ & Z-Value & p-Value & Biatrial & $\mathrm{Bi}$ \\
\hline & Grande AM, 2000 & 1.294 & 0.521 & 3.215 & 0.556 & 0.578 & $317 / 71$ & $9 / 46$ \\
\hline & Solomon NA, 2004 & 0.316 & 0.012 & 8.009 & -0.698 & 0.485 & $0 / 38$ & $1 / 37$ \\
\hline & Koch A, 2005 & 2.307 & 0.993 & 5.358 & 1.944 & 0.052 & $17 / 139$ & $9 / 158$ \\
\hline & Sun JP, 2007 & 1.922 & 0.865 & 4.267 & 1.605 & 0.108 & $17 / 293$ & $10 / 32$ \\
\hline & Kara I, 2012 & 5.750 & 1.902 & 17.379 & 3.100 & 0.002 & $20 / 28$ & $10 / 33$ \\
\hline & Rivinius R, 2017 & 2.159 & 0.087 & 53.470 & 0.470 & 0.638 & $1 / 161$ & $0 / 115$ \\
\hline Rando & & 2.129 & 1.312 & 3.455 & 3.060 & 0.002 & & \\
\hline
\end{tabular}

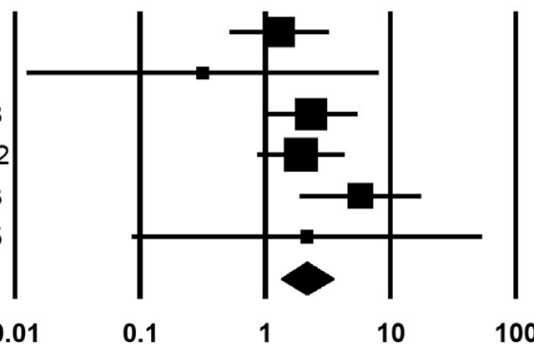

Favors biatrial Favors bicaval

D Early permanent pacemaker implantation

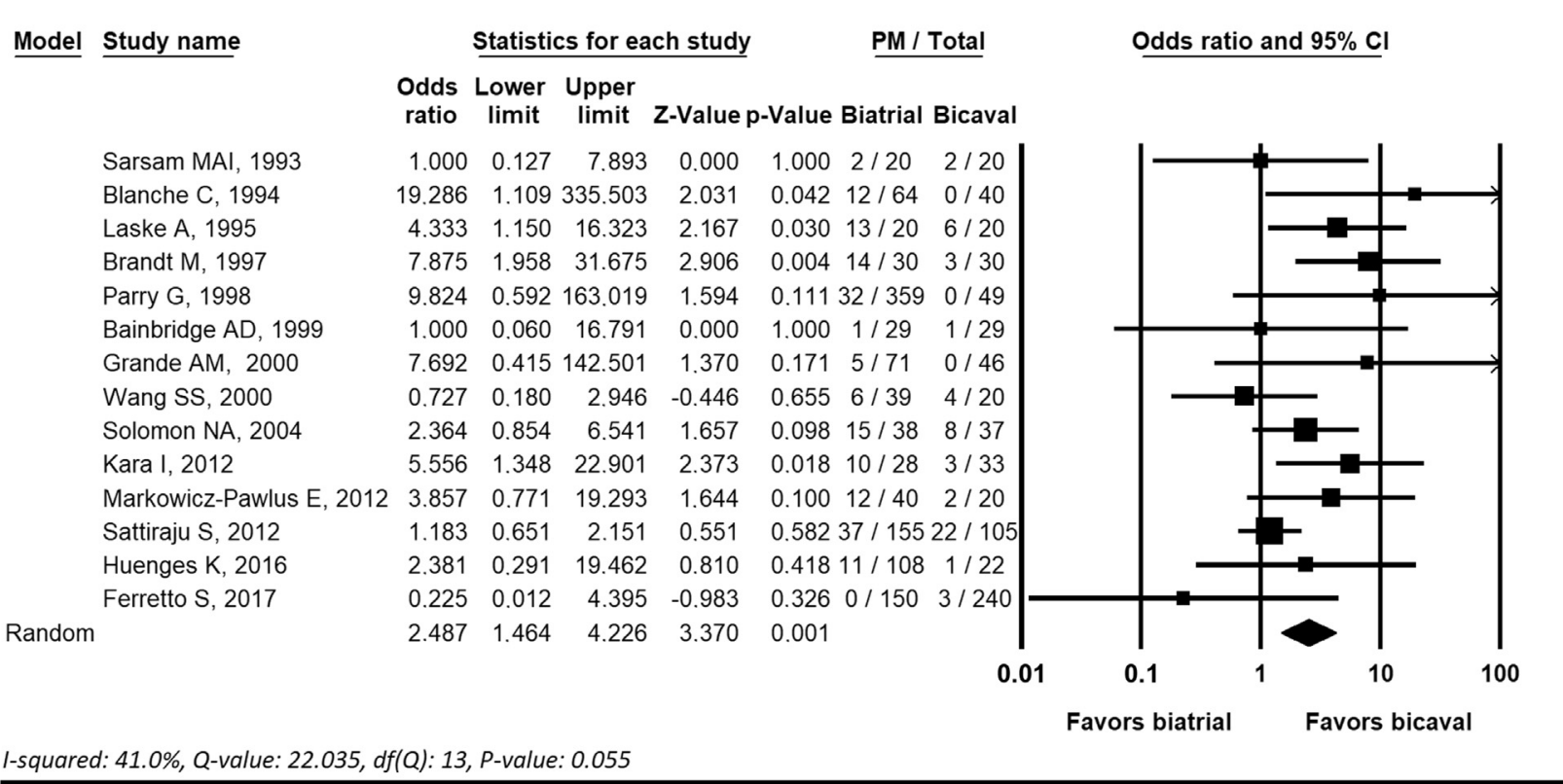

Figure 2. (continued).

Leave-one-out sensitivity analysis did not change the significance of all outcomes.

\section{Comment}

This systematic review and meta-analysis shows that the bicaval technique is associated with superior early and late survival, less early and late tricuspid regurgitation, less early mitral regurgitation, and reduced early need of permanent pacemaker implantation.

Although bicaval OHT can be considered the preferable technique to perform an OHT, there are still many centers worldwide where the biatrial approach is preferred. ${ }^{15}$ More than a decade ago, Schnoor and colleagues ${ }^{6}$ performed a meta-analysis and concluded that early outcomes in the bicaval technique have beneficial effects in comparison with the biatrial technique. More recent overviews of the literature have presented similar conclusions. ${ }^{16,17}$ However, little is known about the difference between these 2 techniques with regard to late outcomes. ${ }^{6}$ Our meta-analysis confirms the association of the bicaval technique with better outcomes in the short term. Moreover, this meta-analysis, with novel contemporary statistics, shows clinically relevant beneficial effects of the bicaval technique in the long term as well. 
Table 2. Pooled Early and Late Outcomes

\begin{tabular}{|c|c|c|c|c|c|c|c|}
\hline Outcome & Variable & Biatrial $(\mathrm{n}=3555)$ & Bicaval $(\mathrm{n}=3208)$ & OR/RR $(95 \% \mathrm{CI})$ & $P$ Value & Studies Reported & $\mathrm{I}^{2}(\%)$ \\
\hline \multirow[t]{4}{*}{ Early } & Mortality & 12.5 (8.30 to 18.4$)$ & $8.80(4.8$ to 15.5$)$ & $1.47(1.0 \text { to } 2.2)^{\mathrm{a}}$ & .048 & 10 & 4.7 \\
\hline & Tricuspid regurgitation & 42.8 (30.8 to 55.7$)$ & 28.5 (20.2 to 38.6$)$ & $1.92(1.4 \text { to } 2.7)^{\mathrm{a}}$ & $<.001$ & 13 & 52.6 \\
\hline & Mitral regurgitation & 11.1 (3.6 to 29.7 ) & $6.9(2.4$ to 17.9$)$ & $2.13(1.3 \text { to } 3.5)^{\mathrm{a}}$ & .002 & 6 & 12.1 \\
\hline & Pacemaker implantation & $19.2(12.2$ to 28.7$)$ & $8.6(4.8$ to 15.0$)$ & $2.49(1.5 \text { to } 4.2)^{\mathrm{a}}$ & .001 & 14 & 34.8 \\
\hline \multirow[t]{4}{*}{ Late } & Mortality & 4.9 (1.1 to 8.7$)$ & $4.1(0.3$ to 7.8$)$ & $1.77(1.2 \text { to } 2.6)^{b}$ & .004 & 4 & 0 \\
\hline & Tricuspid regurgitation & $6.3(3.9$ to 8.6$)$ & $1.2(0.5$ to 2.0$)$ & $2.14(1.2 \text { to } 3.9)^{\mathrm{b}}$ & .014 & 8 & 79.5 \\
\hline & Mitral regurgitation & $0.4(-0.4$ to 1.3$)$ & $0.4(-0.3$ to 1.0$)$ & $1.23(0.6 \text { to } 2.4)^{\mathrm{b}}$ & .528 & 6 & 0 \\
\hline & Pacemaker implantation & $3.3(1.3$ to 5.4$)$ & $1.4(2.0$ to 2.5$)$ & $1.93(0.9 \text { to } 4.1)^{\mathrm{b}}$ & .083 & 8 & 41.5 \\
\hline
\end{tabular}

${ }^{\mathrm{a}} \mathrm{OR} ; \quad{ }^{\mathrm{b}} \mathrm{RR}$

Values are $\%(95 \% \mathrm{CI})$ for early outcomes and linearized occurrence rate as percentage per patient year $(95 \% \mathrm{CI})$ for late outcomes.

$\mathrm{CI}$, confidence interval; OR, odds ratio; RR; rate ratio.

\section{Ischemia Time}

There was a significant difference in the ischemia time between the 2 transplanted groups. Although statistically different, the absolute time difference was only $10 \mathrm{mi}-$ nutes. Cardiopulmonary bypass time and aortic crossclamp time did not differ significantly. The prolonged ischemia time could be explained by the duration of transport or waiting time before or during the operation. In a retrospective study, Russo and colleagues ${ }^{18}$ reviewed ischemia time in 33,640 OHT recipients in the United Network for Organ Sharing (UNOS) database performed between 1987 and 2004 and found no difference in longterm survival (10 years) between prolonged ischemia time (3.50-5.49 hours) and limited ischemia time (0.00-3.49 hours). Taking these observations into account, it seems implausible that a 10 -minute difference would lead to major changes in postoperative outcomes. Nevertheless, as in some selected cases, such as in reoperative heart transplantation or abnormal caval veins, a biatrial approach may still be preferred.

\section{Mortality}

A significant difference was found in both early mortality and late survival between the 2 transplanted groups in favor of the bicaval group. Davies and colleagues ${ }^{19}$ reviewed the UNOS database data between 1997 and 2007 and reported a higher survival rate in the bicaval vs biatrial group after 10 years $(57.4 \%$ vs $51.1 \%)$. The survival rate in the present meta-analysis is higher when compared with Davies and colleagues $(71.2 \%$ vs $60.1 \%){ }^{19}$ This could be due to the fact that Davies and colleagues ${ }^{19}$ used the UNOS database, whereas the individual studies in this meta-analysis mostly reviewed their own patients. Thereby, a strong improvement of the posttransplant care has been seen in the last decade, which has resulted in increased long-term survival. ${ }^{20}$ However, both our metaanalysis and the registry study provide a higher survival rate in the bicaval group after 10 years of follow-up.

\section{Tricuspid Regurgitation}

This study shows a significant difference in early and late tricuspid regurgitation in favor of the bicaval group. Moderate-to-severe tricuspid regurgitation is usually caused by donor-recipient size mismatch, right ventricular failure due to pretransplant pulmonary hypertension, and right ventricular dysfunction due to donor heart rejections. ${ }^{21}$ The cause of donor-recipient size mismatch is mainly a problem of the atria, and the biatrial technique may induce tricuspid regurgitation due to changes in atrial geometry. The bicaval technique only uses the left atrium and both caval veins to perform the anastomosis and, therefore, the technique may prevent tricuspid regurgitation. ${ }^{3}$ Moreover, moderate-tosevere tricuspid regurgitation after OHT could also been caused by torn leaflets and ruptured chordae due to surveillance endomyocardial biopsies in the years after transplantation. ${ }^{22,23}$ It has been shown that patients with no or mild tricuspid regurgitation have better survival than do those with moderate or severe tricuspid regurgitation. ${ }^{24}$ Moderate-to-severe tricuspid regurgitation was, as confirmed by our analysis, reported more often in the biatrial group and therefore could have contributed to a higher mortality rate in this group. ${ }^{25-27}$ However, the optimal treatment of posttransplant severe tricuspid regurgitation is very cumbersome and still not well defined. Generally, because severe tricuspid regurgitation remains asymptomatic for a long time, it is not unusual that conservative treatment is preferred to surgical treatment, probably missing the optimal timing of tricuspid surgery. ${ }^{28}$ Therefore, reduction of occurrence of tricuspid regurgitation by bicaval OHT might be a suitable approach for this post-OHT problem.

\section{Mitral Regurgitation}

Mitral regurgitation post OHT is still not well studied. Mitral regurgitation could be caused by a mismatch in size between the donor heart and native heart, early allograft rejection, left ventricular failure after OHT, and a dilated left atrium. ${ }^{29-31}$ In our study, early mitral regurgitation occurred more frequently in the biatrial transplant group (Figure 2D). However, in late outcomes, no mitral regurgitation was observed. The treatment of mitral regurgitation depends on the severity and symptoms of the patients. Symptomatic severe mitral regurgitation is associated with excess mortality and frequent heart failure. ${ }^{32,33}$ Despite these poor outcomes, only a minority of the affected patients undergo some kind of treatment. ${ }^{32}$ 


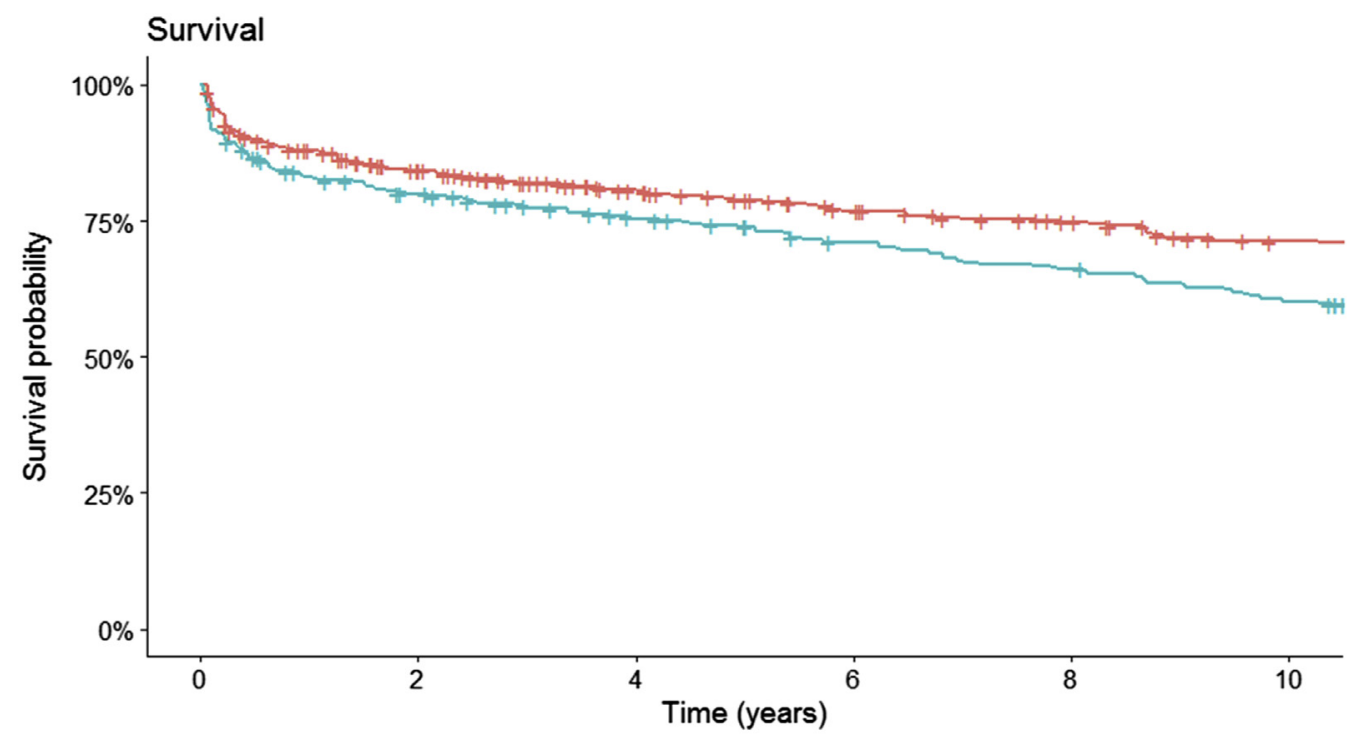

Figure 3. Pooled KaplanMeier curve of patient survival after bicaval (red) or biatrial (green) heart transplantation.

\begin{tabular}{|c|c|c|c|c|c|c|}
\hline \multirow{3}{*}{ 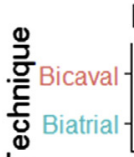 } & \multicolumn{6}{|c|}{ Number at risk } \\
\hline & 1180 & 933 & 775 & 565 & 437 & 372 \\
\hline & 1163 & 915 & 835 & 621 & 579 & 525 \\
\hline 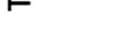 & 0 & 2 & 4 & 6 & 8 & 10 \\
\hline
\end{tabular}

\section{Permanent Pacemaker Implantation}

Early after OHT, sinus node dysfunction and atrioventricular conduction abnormalities are frequently encountered, with some cases in need of permanent pacemaker implantation. ${ }^{34}$ Increased ischemic time, a higher donor age, frequent episodes of rejection, and the anatomy of the blood supply to the sinoatrial node are denoted as causes of sinus node and atrioventricular conduction abnormalities after OHT. ${ }^{35-39}$ However, the most commonly stated cause is surgical trauma at time of transplantation. ${ }^{40}$ Our systematic review and meta-analysis confirms this hypothesis, showing a significant decrease in requirement of early permanent pacemaker implantation in the bicaval group. This is in line with the retrospective study of Davies and colleagues ${ }^{19}$ that showed a higher early pacemaker implantation risk in patients who underwent the biatrial OHT vs bicaval OHT after discharge from the hospital ( $5.1 \%$ vs. $1.9 \%)$. Although Davies and colleagues ${ }^{19}$ also found a higher rate of late pacemaker implantation in the biatrial group, this could not be confirmed in the present study. This may be explained by the fact that only a few studies reported late permanent pacemaker implantation, resulting in insufficient power to show a difference. Another explanation could be that the differences in pacemaker implantation are only presented in the early postoperative period and become comparable with a longer follow-up period. This was also observed by Herre and colleagues, ${ }^{34}$ who noted comparable findings to this metaanalysis.

\section{Strengths and Limitations}

The majority of studies were retrospective in nature, which made them prone to selection bias. ${ }^{41}$ This was confirmed by the fact that most studies scored 6 points on the Newcastle-Ottawa Scale and no points on comparability. Publication bias may have led to an underestimation of the pooled estimates when studies with relatively poor outcomes are not published. However, funnel plots and the Egger's test found no indication for the presence of publication bias. Notwithstanding, some publication bias may be present based on visual inspection of the funnel plots. There was moderate-to-substantial heterogeneity between studies in most outcomes, which may potentially have led to inaccurate results. Another limitation was caused by the limited availability of posttransplant clinical data about the number and severity of rejections and cardiac transplant vasculopathy in the 2 groups, as these factors are known to influence the long-term prognosis. Furthermore, studies over a large time span were included in the meta-analysis. Nevertheless, subgroup analyses yielded comparable outcomes of both older and contemporary studies.

\section{Conclusion}

This systematic review with meta-analysis provides ample evidence that bicaval OHT is associated with better early and late clinical outcomes, including early and late survival, prevention of tricuspid regurgitation, and need of permanent pacing.

The authors thank Wichor M. Bramer for his help in developing a search strategy. 


\section{References}

1. Metra M, Ponikowski P, Dickstein K, et al. Advanced chronic heart failure: a position statement from the Study Group on Advanced Heart Failure of the Heart Failure Association of the European Society of Cardiology. Eur J Heart Fail. 2007;9:684-694.

2. Lower RR, Shumway NE. Studies on orthotopic homotransplantation of the canine heart. Surg Forum. 1960;11:18-19.

3. Yacoub M, Mankad P, Ledingham S. Donor procurement and surgical techniques for cardiac transplantation. Semin Thorac Cardiovasc Surg. 1990;2:153-161.

4. Leyh RG, Jahnke AW, Kraatz EG, Sievers HH. Cardiovascular dynamics and dimensions after bicaval and standard cardiac transplantation. Ann Thorac Surg. 1995;59:1495-1500.

5. Freimark D, Silverman JM, Aleksic I, et al. Atrial emptying with orthotopic heart transplantation using bicaval and pulmonary venous anastomoses: a magnetic resonance imaging study. J Am Coll Cardiol. 1995;25:932-936.

6. Schnoor M, Schäfer T, Lühmann D, Sievers HH. Bicaval versus standard technique in orthotopic heart transplantation: a systematic review and meta-analysis. J Thorac Cardiovasc Surg. 2007;134:1322-1331.e7.

7. El-Gamel A, Deiraniya AK, Rahman AN, Campbell CS, Yonan NA. Orthotopic heart transplantation hemodynamics: does atrial preservation improve cardiac output after transplantation? J Heart Lung Transplant. 1996;15:564-571.

8. Moher D, Liberati A, Tetzlaff J, Altman DG; PRISMA Group. Preferred reporting items for systematic reviews and metaanalyses: the PRISMA statement. J Clin Epidemiol. 2009;62: 1006-1012.

9. Wells G, Shea B, O'Connell D, Peterson J, Welch V, Losos M. The Newcastle-Ottawa Scale (NOS) for Assessing the Quality of Nonrandomised Studies in Meta-analyses. Available at: http://www.ohri.ca/programs/clinical_epidemiology/oxford. asp. Accessed November 30, 2018.

10. Borenstein M, Hedges L, Higgins J, Rothstein H. Fixed-Effect versus Random-Effects Models: Introduction to Meta-Analysis. Chichester, United Kingdom: Wiley; 2009.

11. Borenstein M, Hedges LV, Higgins JP, Rothstein HR. A basic introduction to fixed-effect and random-effects models for meta-analysis. Res Synth Methods. 2010;1:97-111.

12. Peters JL, Sutton AJ, Jones DR, Abrams KR, Rushton L. Comparison of two methods to detect publication bias in meta-analysis. JAMA. 2006;295:676-680.

13. Guyot P, Ades AE, Ouwens MJ, Welton NJ. Enhanced secondary analysis of survival data: reconstructing the data from published Kaplan-Meier survival curves. BMC Med Res Methodol. 2012;12:9.

14. Mitchell M, Muftakhidinov B, Winchen T. Engauge Digitizer Software. Available at: http://markummitchell.github.io/ engauge-digitizer. Accessed January 17, 2019.

15. Jungschleger JGM, Boldyrev SY, Kaleda VI, Dark JH. Standard orthotopic heart transplantation. Ann Cardiothorac Surg. 2018;7:169-171.

16. Morgan JA, Edwards NM. Orthotopic cardiac transplantation: comparison of outcome using biatrial, bicaval, and total techniques. J Card Surg. 2005;20:102-106.

17. Jacob S, Sellke F. Is bicaval orthotopic heart transplantation superior to the biatrial technique? Interact Cardiovasc Thorac Surg. 2009;9:333-342.

18. Russo MJ, Chen JM, Sorabella RA, et al. The effect of ischemic time on survival after heart transplantation varies by donor age: an analysis of the United Network for Organ Sharing database. J Thorac Cardiovasc Surg. 2007;133:554-559.

19. Davies RR, Russo MJ, Morgan JA, Sorabella RA, Naka Y, Chen JM. Standard versus bicaval techniques for orthotopic heart transplantation: an analysis of the United Network for Organ Sharing database. J Thorac Cardiovasc Surg. 2010;140: 700-708.e2.

20. Zijlstra LE, Constantinescu AA, Manintveld O, et al. Improved long-term survival in Dutch heart transplant patients despite increasing donor age: the Rotterdam experience. Transpl Int. 2015;28:962-971.
21. Birnbaum J, Ulrich SM, Schramm R, et al. Transient severe tricuspid regurgitation after transplantation of an extremely oversized donor heart in a child-Does size matter? A case report. Pediatr Transplant. 2017;21:12863.

22. Fiorelli AI, Coelho GH, Aiello VD, et al. Tricuspid valve injury after heart transplantation due to endomyocardial biopsy: an analysis of 3550 biopsies. Transplant Proc. 2012;44:2479-2482.

23. Cooper LT, Baughman KL, Feldman AM, et al. The role of endomyocardial biopsy in the management of cardiovascular disease: a scientific statement from the American Heart Association, the American College of Cardiology, and the European Society of Cardiology. Circulation. 2007;116:2216-2233.

24. Wartig M, Tesan S, Gäbel J, et al. Tricuspid regurgitation influences outcome after heart transplantation. J Heart Lung Transplant. 2014;33:829-835.

25. Nath J, Foster E, Heidenreich PA. Impact of tricuspid regurgitation on long-term survival. J Am Coll Cardiol. 2004;43:405-409.

26. Sadeghpour A, Hassanzadeh M, Kyavar M, et al. Impact of severe tricuspid regurgitation on long term survival. Res Cardiovasc Med. 2013;2:121-126.

27. Agricola E, Stella S, Gullace M, et al. Impact of functional tricuspid regurgitation on heart failure and death in patients with functional mitral regurgitation and left ventricular dysfunction. Eur J Heart Fail. 2012;14:902-908.

28. Chan MC, Giannetti N, Kato T, et al. Severe tricuspid regurgitation after heart transplantation. J Heart Lung Transplant. 2001;20:709-717.

29. Stevenson LW, Dadourian BJ, Kobashigawa J. Mitral regurgitation after cardiac transplantation. Am J Cardiol. 1987;60:119-122.

30. Strauss RH, Stevenson LW, Dadourian BA, Child JS. Predictability of mitral regurgitation detected by Doppler echocardiography in patients referred for cardiac transplantation. Am J Cardiol. 1987;59:892-894.

31. Boltwood CM, Tei C, Wong M, Shah PM. Quantitative echocardiography of the mitral complex in dilated cardiomyopathy: the mechanism of functional mitral regurgitation. Circulation. 1983;68:498-508.

32. Dziadzko V, Clavel MA, Dziadzko M, et al. Outcome and undertreatment of mitral regurgitation: a community cohort study. Lancet. 2018;391:960-969.

33. Baskett RJ, Exner DV, Hirsch GM, Ghali WA. Mitral insufficiency and morbidity and mortality in left ventricular dysfunction. Can J Cardiol. 2007;23:797-800.

34. Herre JM, Barnhart GR, Llano A. Cardiac pacemakers in the transplanted heart: short term with the biatrial anastomosis and unnecessary with the bicaval anastomosis. Curr Opin Cardiol. 2000;15:115-120.

35. Cooper MM, Smith CR, Rose EA, Schneller SJ, Spotnitz HM. Permanent pacing following cardiac transplantation. J Thorac Cardiovasc Surg. 1992;104:812-816.

36. Jacquet L, Ziady G, Stein K, et al. Cardiac rhythm disturbances early after orthotopic heart transplantation: prevalence and clinical importance of the observed abnormalities. I Am Coll Cardiol. 1990;16:832-837.

37. Miyamoto Y, Curtiss EI, Kormos RL, Armitage JM, Hardesty RL, Griffith BP. Bradyarrhythmia after heart transplantation. Incidence, time course, and outcome. Circulation. 1990;82:IV313-IV317.

38. DiBiase A, Tse TM, Schnittger I, Wexler L, Stinson EB, Valantine HA. Frequency and mechanism of bradycardia in cardiac transplant recipients and need for pacemakers. Am J Cardiol. 1991;67:1385-1389.

39. Chau EM, McGregor CG, Rodeheffer RJ, et al. Increased incidence of chronotropic incompetence in older donor hearts. J Heart Lung Transplant. 1995; 14:743-748.

40. Heinz G, Kratochwill C, Schmid S, et al. Sinus node dysfunction after orthotopic heart transplantation: the Vienna experience 1987-1993. Pacing Clin Electrophysiol. 1994; 17:2057-2063.

41. Song JW, Chung KC. Observational studies: cohort and casecontrol studies. Plast Reconstr Surg. 2010;126:2234-2242. 